Available online on 15.06.2020 at http://jddtonline.info
Open Access to Pharmaceutical and Medical Research
(c) 2011-18, publisher and licensee JDDT, This is an Open Access article which permits
unrestricted non-commercial use, provided the original work is properly cited

Open $\odot$ Access

Research Article

\title{
Histological study of the effects of aluminum chloride exposure on the brain of wistar rats female
}

Bekhedda Hadjer*, Menadi Norredine, Demmouche Abbassia, Ghani Abdelaziz, Mai Hicham

Biotoxicology laboratory. Department of biology, Faculty of Natural Science and life. University Djilali Liabes Sidi Bel Abbes, Algeria

\begin{abstract}
Introduction: Aluminum ( $\mathrm{Al}$ ) has the potential to be neurotoxic in human and animals, is present everywhere in the environment, many manufactured foods and medicines and is also added to drinking water for purification purposes and tooth paste cosmetic products They accumulate in living organisms and disrupt balances, and accumulate in the body biological systems, causing toxic effects (They may affect the nervous system, kidney, liver, respiratory or other functions). Nervous system is a vulnerable target for toxicants due to critical voltages which must be maintained in the cells and the all responses when voltages reach threshold levels.
\end{abstract}

Objective This study aimed to expose the impact of aluminum chloride (AlCl3) on brain architecture.

Methods: In our study, twenty healthy female rats were intraperitoneal administered of aluminum chloride (ALCL3) at 10 mg / kg body weight with consecutively for 15 day

Result. The results showed a highly significant reduction in body weight $(\mathbf{p}<\mathbf{0 . 0 0 0 1}$. This is because aluminum has an anorectic effect contrariwise, there is no significant impact of aluminium exposure has been observed with respect to brain weight and relative brain weight respectively $(\mathbf{p}<\mathbf{0 . 9 1 2}),(\mathbf{p}<\mathbf{0 . 4 5})$.

The histological study describes the alterations in the brain marked tissue necrosis and cytoplasmic vacuolations and karyopyknosis of neuronal cells of the brain.

Conclusion; Aluminum is a toxic heavy metal and a ubiquitous environmental pollutant. It can alter the permeability of the blood-brain barrier and enter the brain, severely affecting the functioning of the nervous system.

Keywords: Toxicity, brain, Aluminium chloride, Rats female, necrosis.

Article Info: Received 21 March 2020; Review Completed 28 April 2020; $\quad$ Accepted 11 May 2020; Available online 15 June 2020

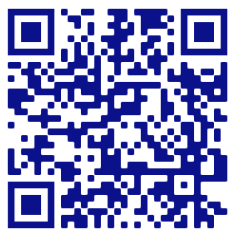

\section{Cite this article as:}

Bekhedda H, Menadi N, Demmouche A, Ghani A, Mai H, Histological study of the effects of aluminum chloride exposure on the brain of wistar rats female, Journal of Drug Delivery and Therapeutics. 2020; 10(3-s): 37-42 http://dx.doi.org/10.22270/jddt.v10i3-s.4152

Bekhedda Hadjer, Biotoxicology laboratory. Department of biology, Faculty of Natural Science and life. University Djilali Liabes Sidi Bel Abbes, Algeria

\section{Abbreviation:}

Alcl3: aluminum chloride

$\mathrm{cm}$ : centimeter

D: day

IP: interperitoneal injection

H: hour

g: gram

Kg: kilogram

mg: milligram

$\mathrm{al}^{3+}$ :cation of aluminium

(H\&E):Haematoxylin and eosin 


\section{INTRODUCTION}

The human brain is the control centre of the human nervous system. It receives signals from the body's sensory organs and transmits information to the muscles. It has the same basic structure as other mammalian brains, consisting of more than 100 billion nerves that communicate through trillions of connections called synapses

Aluminum is a trivalent cation found in its ionic form in most types of animal and plant tissue and in natural waters everywhere 1.

The transport of essential and non-essential metal ions across membrane barriers, such as the blood-brain barrier, is mediated by specific transport mechanisms due to their size, although receptor-mediated uptake is a possible mechanism that regulates brain levels of different metals ${ }^{2}$.

The blood-brain barrier is normally only permeable to small molecules, or to larger molecules, such as proteins, by active transport mechanisms. Because of this low permeability, it is important to understand the mechanisms by which aluminum crosses the barrier.

Aluminum chloride has been implicated for its adverse effects on behavioural parameters in Wistar rats (for its effects on behaviour), for its adverse effects on anxietyrelated behaviour in Wistar rats by increasing anxiety levels in aluminum-treated rats, and for its neurodegenerative effects on the histology of the cerebral cortex in adult Wistar rats, particularly at high doses $\mathbf{3 , 4 , 5}$ as the brain is a preferred site of aluminum accumulation in grey and white matter, primarily in certain cortical regions and on the hippopotamus campus 6,7,8 .

Aluminium is one of the trace elements with a moderate toxic effect on living organism 9 .

Chronic exposition to this trace element can cause alterations in skeletal, nervous, hematopoietic and respiratory systems $\mathbf{1 0 , 1 1 , 1 2 , 1 3}$.

The effect depends on the dose, the Al compound used and the particular animal model. It can show a discrepancy from death to behavioural change (memory loss), loss of weight or slight changes in Al buildup in bone 14, 15.

This study was aimed at evaluating the histological effects that Aluminium Chloride Exposure could have on the brain determined and to determine the possible effects on the body weight / relative brain weight of Wistar Rats female.

\section{MATERIALS AND METHODS:}

The ground-breaking studies on Aluminium neurotoxicity in experimental animals were initially described in 1886 by Siem and Dollken 16. This experiment was conducted in the Department of biology Faculty of Natural Science and life University Djillali Liabes Sidi Bel Abbes Algeria. The rules and regulations governing animal handling were observed.

\section{Experimental Animals:}

Twenty adult Wistar rats were used for this experiment. The Wistar rats were housed in steel cages in the animal house of Department of biology, they were given sufficient food, water and kept under good ventilation. The Wistar rats were kept for two weeks before commencement of aluminum chloride administration. This was to enable the Wistar rats acclimatized to the environment.

\section{Experimental Design:}

The study comprised 20 female Wistar rats divided into two groups of ten for this experiment.

The Wistar rats were housed in a stainless steel cages maintained at standard environmental conditions $(12 \mathrm{~h}-12 \mathrm{~h}$ light-dark cycle with light on at AM) with sufficient food, water and under good ventilation

All the rats were acclimatized for 2 week before the test, and randomly divided into four equal groups:

The wistar rats were divided into two groups.:

Control group I: was given $\mathrm{NaCl} 0.9$.

Group II: received $10 \mathrm{mg} / \mathrm{Kg}$ body weight ALCL3 for five teen days (15D)

Aluminum chloride administered to female rats via injection intrapertoneale.

\section{Statistical analysis}

The Weights of the Wistar rats were taken before the commencement of administration and later re-weighted after expiration of two weeks of the experiment with the aid of weighing balance. The weights were recorded before and after administration; and they were tested statistically. All of the data are expressed as the means \pm standard deviation (SD) from at least three independent experiments with different batches of cells. Differences between groups were analysed by one-way analysis of variance (ANOVA) using SPSS 20 software and followed by the post hoc Fisher's Least Significance Difference (LSD) test, with P.

\section{Histopathologique examinations in brain}

The Wistar rats were humanely sacrificed by anesthetizing them in a suffocating chamber using chloroform, after the end of the experiment, animals were sacrificed by decapitation and brain were immediately removed and immediately fixed in $10 \%$ formalin. After fixation, the tissues were transferred into an automatic processor where they went through a process of dehydration in ascending grades of alcohol (ethanol) 70\%, 80\%, 95\% and absolute alcohol for 2 changes each.

The tissues were then cleared in xylene and embedded in paraffin wax. Serial sections of 5 micron thick were obtained using a rotary microtome. The tissue sections were deparaffinised hydrated and stained using the routine haematoxylin and eosin staining method (H\&E). The stained sections were examined under the light microscope fitted to a digital camera and lap top. The histological sections of the gonads were made in the pathology laboratory of hospital Abdelkader Hassani in Sidi Bel abbes. Algeria

\section{RESULTS}

\section{a. Microscopic Examination of Tissues (H\&E stain):}

The tissue was processed and stained with Haematoxylin and eosin (H\&E).

The stained sections of cerebral cortex were examined under the light microscope.

No rats died during the experiment.

> Photomicrographs of rat brain sections stained with haematoxylin and eosin (bar=25 $\mu \mathrm{m})$. The normal histological structure of Cerebral Cortex in rats brain with intact neurons and glial cell were seen in control animals.(plate 1) 
Section A



Plate 1: The histological analysis of Cerebral Cortex tissue in rats' brain stained with H\&E (control group) Section A (Magnification X 10) / Section B . (Magnification X 40).

Group II treated showed slight sign of degeneration with slight cell distortion karyopyknosis of neuronal cells and vacuolation of the cerebral cortex plate 02 and the necrosis in the brain parenchyma plate 03

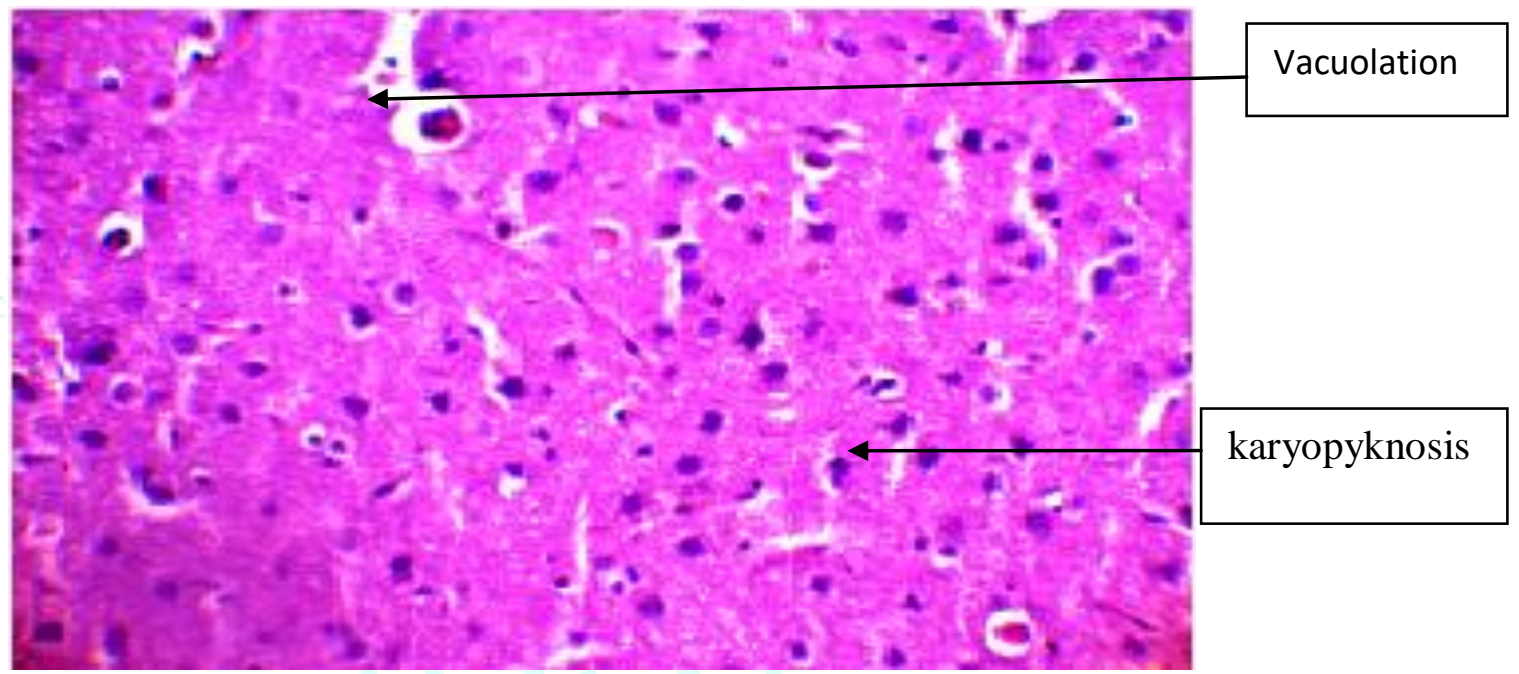

Plate2: The histological analysis indicated slight neuronal vacuolation of the Cerebral Cortex of Wistar rats of experimental animals group II, stained with H\&E. (Magnification X 40).

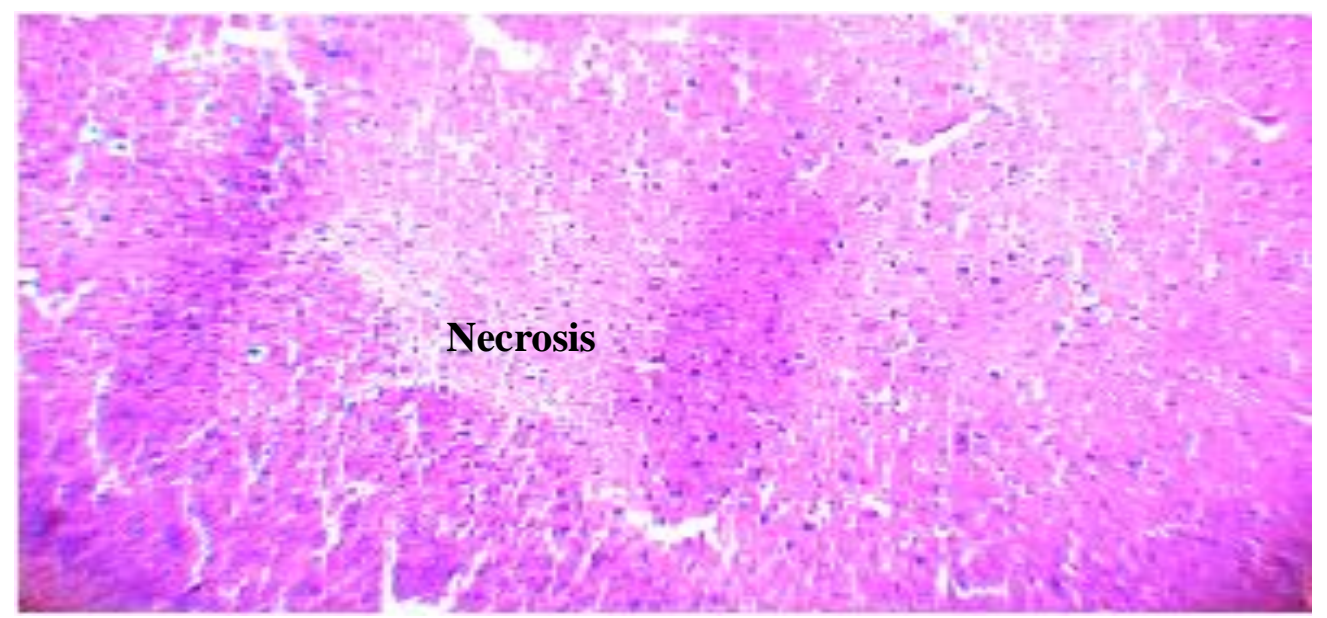

Plate 3: The histological analysis indicated showing necrosis of the Cerebral Cortex in rats' brain of Al-treated rats. Group II stained with H\&E. (Magnification X 10). 
The histological study showed alterations in the cerebral cortex marked by a Cellular degeneration.

\section{b. Evolution of body weight and relative brain weight}

Weight monitoring is performed in aluminum intoxicated rats as well as in controls.

\section{Evolution of body weight:}

Aluminum chloride administered to female rats $(10 \mathrm{mg} / \mathrm{kg}$ BW) intrapertoneale at $\mathbf{1 0} \mathbf{~ m g} / \mathbf{k g}$ to rats twice a week resulted in a significant reduction in body weight in the intoxicated group compared to control group. (Table 1).
Intoxication with aluminum chloride at $10 \mathrm{mg} / \mathrm{kg}$ throughout the two weeks of experimentation administered intrapertoneale to different batches of rats resulted in a significant decrease in body weight in group II (prepubescent group) compared to the control group $(\mathrm{p}<0.0001)$.

This is due to the fact that aluminum has an anorectic effect and influences the nerve pathways responsible for controlling satiety.

Table 1: shows mean body by the groups of rats during the two weeks experiment.

\begin{tabular}{|c|c|c|c|c|c|c|}
\hline \multicolumn{6}{|c|}{ Group Statistics } & \multirow[b]{2}{*}{$\mathrm{P}^{*}$} \\
\hline & rats wistar & $\mathrm{N}$ & Mean & $\begin{array}{l}\text { Standard } \\
\text { type }\end{array}$ & $\begin{array}{l}\text { Mean erreur } \\
\text { standard }\end{array}$ & \\
\hline \multirow{2}{*}{$\begin{array}{l}\text { Body } \\
\text { Weight }\end{array}$} & Control group & 10 & 163,27 & 4,818 & 1,244 & \multirow[b]{2}{*}{$<0.0001$} \\
\hline & Group II Alcl3 & 10 & 142,40 & 16,526 & 4,267 & \\
\hline
\end{tabular}

Results are presented as means \pm SE $(n=10)$

$\mathrm{S}$ : Significant change at $\mathrm{P}<0.05, \mathrm{a}$ : Compared to control untreated

\section{Evolution brain weight}

No significant reduction was observed in the relative brain weight of the brain of the intoxicated group compared to the control group in the primary analysis. (Table 2).

In the present study, aluminum chloride intoxication at 10 $\mathrm{mg} / \mathrm{kg}$ administered by injection to the peritoneum of rats resulted in a significant decrease in body weight of pups exposed to aluminum.
The present investigation demonstrates that the aluminum exposure, in the present dose and duration, does not affect the brain weight.

No significant impact of aluminum exposure has been observed with respect to brain weight (table.2) of the treated animals.

Table 2: Effect of aluminium chloride $(10 \mathrm{mg} / \mathrm{kg})$ on the change in brain weight that results from AlCl3 treatment alone

\begin{tabular}{|c|c|c|c|c|c|c|}
\hline \multicolumn{6}{|c|}{ Group statistics } & \multirow[b]{2}{*}{$\mathrm{P}$} \\
\hline & Wistar Rats & $\mathrm{N}$ & Mean & $\begin{array}{l}\text { Standard } \\
\text { type }\end{array}$ & $\begin{array}{l}\text { Mean erreur } \\
\text { standard }\end{array}$ & \\
\hline \multirow{2}{*}{$\begin{array}{l}\text { brain } \\
\text { Weight }\end{array}$} & Control group I & 10 & 1,603 & 0,1588 & 0,14314 & \multirow[b]{2}{*}{$\perp 0,912$} \\
\hline & Group II Alcl3 & 10 & 1,586 & 0,1903 & 0,14314 & \\
\hline
\end{tabular}

Results are presented as means \pm SE $(n=10)$

$S$ : Significant change at $\mathrm{P}<0.05$, a: Compared to control untreated

Data are presented as mean \pm S.E.M. $(n=10)$ ns non-significant in comparison to control.

$* p<0.05$ in comparison to Group I (untreated control rats).

${ }_{-} p<0.05$ in comparison to Group II (AlCl3 treated rats).

$\perp$ Non-significant in comparison to Group II (AlCl3 treated rats).

Exposure to $\mathrm{AlCl} 3$ resulted in a significant $<0.0001$ decrease in body weight in the pre pubertal group compared to the control group. 


\section{Evolution relative brain weight}

Relative brain weight in experimental and control animals during the course of aluminium exposure is presented in Fig. 1.

No significant Effect of aluminium chloride $(10 \mathrm{mg} / \mathrm{kg})$ has been observed on the change in relative brain weight that results from $\mathrm{AlCl} 3$ treatment alone

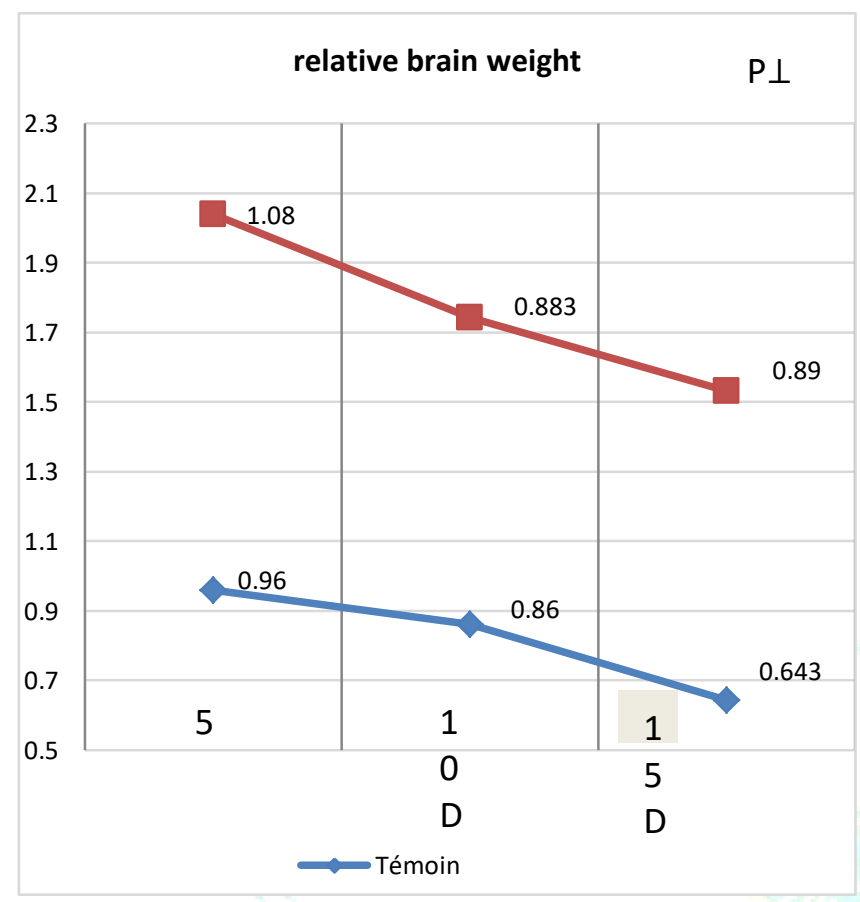

Figure 1: Variation of the relative's weight of the brain according to the treatment.

Data are presented as mean \pm S.E.M. $(n=10)$ non-significant in comparison to control.

$* p<0.05$ in comparison to Group I (untreated control rats).

_ $P<0.05$ in comparison to Group II (AlCl3 treated rats).

$\perp$ Non-significant in comparison to Group II (AlCl3 treated rats).

\section{DISCUSSION:}

Weight is the amount or quantity of heaviness or mass; it is system of units for expressing heaviness or mass: measure of the heaviness of an object; the amount anything weighs 17.

The present study revealed that the administration of aluminium chloride to rats decrease in weight of body during the experiment in rats intoxicated by aluminum chloride

This weight loss may be due to disruption of intestinal absorption; aluminum compounds are known to inhibit gastrointestinal mobility $\mathbf{1 8}$ and slow gastric emptying in humans and rats 19.

On the other hand, Duterte-Boucher et al. (1988) found a decrease in weight during the experiment in rats intoxicated by aluminum chloride; this decrease is probably due to the anorectic effect of aluminum, since aluminum acts on the decrease in the synthesis pathways of serotonin and dopamine levels, these two neurotransmitters being directly involved in the regulation of digestive and dietary behaviour and the control of satiety 20.

The cerebral cortex is the key structures of memory formation. It also integrates higher mental functions, general movement, visceral functions, and behavioral reactions 21,22 .

For cerebral histological structure We observed that the treatment of rattles with aluminum chloride affects the arterial structure of the cerebral cortex with the appearance of cell degeneration, vacuolation and a necrosis characterized by fibrosis (plate 02-03) compared to control lot who present a large number of normal neurons accompanied by glial cells ( plate 01)

Aluminium is a toxic heavy metal and a ubiquitous environmental pollutant. It can alter the permeability of the blood-brain barrier and enter the brain severely affecting the functioning of the nervous system

These results are similar to the data reported by ${ }^{3}$ who indicated that exposure of rats to $\mathrm{AlCl} 3$ for eight weeks would induce severe neurodegeneration at the level of the hippocampus demonstrated by histological studies.

According to Crapper et al. (1980), aluminium concentration was elevated in neurons containing neurofibrillary tangles and perhaps within senile plagues, however, aluminium might accumulate in neurons $\mathbf{2 3 .}$

Aluminium is a highly neurotoxic element and has been reported to play a role in degeneration of nerve cel ls in the brain of human and experimental animals $\mathbf{2 4}$.

Secondarily to intracellular degenerating changes and the neuropathological and behavioural changes following the aluminium exposure were similar to those observed in Alzheimer's disease, this is in line with Muller et al. (1990), who suggested that aluminium might have a role in the pathogenesis of Alzheimer's disease although based on circumstantial evidence 25 .

We therefore concluded that administration of aluminium chloride has a neurodegenerating effects (damage) on the hippocampus of Wistar rats as shown in Plate 3-5.

\section{CONCLUSION:}

Aluminum is a toxic heavy metal and a ubiquitous environmental pollutant.

Aluminum toxicity results due to an exposure to large amounts of $\mathrm{Al}$ containing compounds or direct inoculation of $\mathrm{Al} \mathrm{Al3}+$ exposures have been associated with the development of the most common neurodegenerative disorders, the molecular mechanisms behind the Al3+ transport in neurons and subsequent neuron damage has remained elusive $\mathbf{2 6}$ and It can alter the permeability of the blood-brain barrier and enter the brain 27 severely affecting the functioning of the nervous system $\mathbf{2 8}$.

In the brain aluminium accumulates in the sensitive area such as hippocampus and frontal cortex and is considered as a contributing factor in the pathogenesis of neurodegenerative diseases $\mathbf{2 9}$ and is also involved in skeletal, haematological diseases. The results of the present study indicated that aluminium is a highly neurotoxic and that was capable of causing pronounced alterations in some could cause neurodegeneration histopathological changes associated with cell degeneration, vacuolation and a necrosis in the cortex and parenchyma cerebral. Consequently, the study recommended that attention should be paid to reduce the sources of exposures to aluminium. 


\section{POTENTIAL CONFLICT OF INTEREST}

There are no conflicts of interest.

All authors are in agreement with the content of the manuscript.

The authors confirm that our work does not violate the policies established by the journal.

The Author(s) warrants and affirms that:

The Manuscript is an original work and sole property of the Author(s) and that the manuscript has not been published elsewhere nor it is currently under consideration for publication by another journal.

\section{REFERENCES:}

1. Jiang, H., Teng, R., Wang, Q., Zhang, X., Wang, H., Wang, Z., Cao, J., and Teng, L. (2008). Transcriptional analysis of estrogen receptor alpha variant mRNAs in colorectal cancers and their matched normal colorectal tissues. J. Steroid Biochem. Mol. Biol. 112, 20-24.

2. Bressler JP, Olivi L, Cheong JH, Kim Y, Maerten A, Bannon D. Metal transporters in intestine and brain: their involvement in metalassociated neurotoxicities. Hum Exp Toxicol 2007; 26: $221-9$.

3. Buraimoh AA and Ojo SA. Effects of Aluminium Chloride Exposure on the Histology of the Stomach of Wistar Rats. Int J Pharm. Bio Sci.; Oct-Dec.2012b; vol2, Issue4, 266-276.

4. Buraimoh. A.A, S.A. Ojo, J.O. Hambolu and S.S. Adebisi, Asian J. Biol. Sci, 2012c, 3 (2): 435-438.

5. Buraimoh A.A. S.A. Ojo, J.O. Hambolu and S.S. Adebisi, American Medical Journal, 2012d, 3(2): 210-219.

6. M. Kawahara .Effects of aluminum on the nervous system and its possible link with neurodegenerative diseases J. Alzheimers Dis., 8 (2005), pp. 171-182.

7. A.C. Miu, C.E. Andreescu, R. Vasiu, A.I. OlteanuA behavioral and histological study of the effects of long-term exposure of adult rats to aluminumInt. J. Neurosci., 113 (2003), pp. 1197-1211.

8. Walton, J.R.; Brain lesions comprised of aluminum-rich cells that lack microtubules may be associated with the cognitive deficit of Alzheimer's disease Neurotoxicology, 30 (2009), pp. 1059-1069.

9. Graczyk A., Radomska K., Długaszek M. Synergizm i antagonizm między biopierwiastkami i metalami toksycznymi. Ochrona Środowiska i Zasobów Naturalych nr 18. Instytut Ochrony Środowiska. Warszawa, pp39-45, 1999

10. Plieth C., Sattelmacher B., Hansen U.P., Knight M.R. Low-pHmediated in cytosolic calcium are inhibited by aluminium: a potential mechansm for aluminium toxicity. Plant.J.18 (6), 643, 1999.

11. Afifi A. Renal osteodystrophy in developing countries. Artif.Organs. 26 (9), 767, 2002.

12. Chen J., Wang M., Run D., She J. Early chronic aluminium exposure impairs long-term potentaion and depression to the rat dentate gyrus in vivo. Neuroscience,112 (4), 879, 2002.

13. Campbell A. The potential role of aluminium in Alzheimers disease. Nephrol.Dial. Transplant. 17,supl 2,17, 2002.

14. Y.L. Chan, A.C. Alfrey, S. Posen, D. Lissner, E. Hills, C.R. Dunstan and R.A. Evans, Calcif Tissue Int., 1983; 35: 344351.

15. Bräunlich H. C. Fleck, L. Kersten, G. Stein, V. Laske, A. Müller and E. Keil, J Appl Toxicol, 1986; 6: 55-59.

16. Terry R. D. and Pena C. Experimental production of neurofibrillary degeneration..Neuropath. Exp. Neurol. 24: (1965) 200-21

17. A. Christine, the American Heritage Dictionary of Idioms. Published by Houghton Mifflin. 1997.

18. Hava M. AND Hurwtiz A. (IW3). The relaxing effect of aluminum and lanthanum on rat and human gastric smooth muscle in vitro. Eur. J. Plnrmncol. 22 : I 56- I 6 I ; 1973.

19. Hurwitz A. Robinson R. G,Vats T-S., Whittier F. C. AND Herin W.F. (1976). Effects of antacids on gristric emptying. Gastroenterolog7yI : 268-273.

20. Duterte-Boucher $\mathrm{D}$, Leclère J-F, Panissaud C, Costentin J. Acute effects of direct dopamine agonists in the mouse behavioral despair test. European Journal of Pharmacology. September 1988. Volume 154, Issue 2, 13, Pages 185-190.

21. Brodal, S., 1992. The Central Nervous System: Structure and Function. Oxford University Press, Oxford. Cowling, S.J., A.M. Gunn and D.A. Winnard, 1991. Aluminium Speciation in drinking water. Report no. FR0192.

22. Cauller, L. (1995). Layer I of primary sensory neocortex: where top-down converges upon bottom-up. Behav Brain Res., 71(1-2):163-70. PMID 874718.

23. Crapper, D.R., S.S. Quittkat, Krishman, A.J. Dalton and U. De Boni, 1980. Intranuclear aluminum content in Alzheimer's disease, dialysis encephalopathy and experimental aluminum encephalopathy acta Neuropathology, 50: 19-24.

24. Linton RW, Bryan SR, Grif fis DP, Shelburne JD, Fiori CE, Gar ruto RM. Digital imaging studies of aluminum and calcium in neurofibrillarytangle-bearing neurons using secondary ion mass spect romet ry. Trace Elem. Med., 1987: 4: 99-104.

25. Muller,G., V. Bernuzzi, D. Desor, M.F. Hutin, D. Burnel and P.R. Lher, 1990. Developmental alteration in offspringoffemalerats orally intoxicated by aluminum lactate at different gestation periods. Teratol., 42: 253-261.

26. N. VanDuyn, R. Settivari, J. LeVora, S. Zhou, J. Unrine, R. Nass, The metal transporter SMF-3/DMT-1 mediates aluminuminduced dopamine neuron degeneration, J. Neurochem. 124 (2013) 147-157

27. Shukla, A., Shukla, G.S., Srimal, R.C., 1996. Cadmium-induced alterations in blood-brain barrier permeability and its possible correlation with decreased microvessel antioxidant potential in rat. Hum. Exp. Toxicol. 15, 400-405

28. Wang, B., Du, Y., 2013. Cadmium and its neurotoxic effects. Oxid. Med. Cell. Longev. 2013898034.

29. M. Nampoothiri, J. John, N. Kumar, J. Mudgal, G.K. Nampurath, M.R. Chamallamudi, Modulatory role of simvastatin against aluminium chloride-induced behavioural and biochemical changes in rats, Behav. Neurol. 2015 (2015) 1-9. 